\title{
Mental Education of Football Referees: Mental Suitcase of Modern Football Referees
}

\author{
Mustafa Serdar Terekli ${ }^{1} \&$ Halil Orbay Çobanoğlu ${ }^{2}$ \\ ${ }^{1}$ Department of Sports Management, Faculty of Sports Sciences, Eskişehir Technical University, Eskişehir, \\ Turkey \\ ${ }^{2}$ Ministry of National Education, Muzaffer Çil Anadolu High School, Eskişehir, Turkey \\ Correspondence: Halil Orbay Çobanoğlu, Ministry of National Education, Muzaffer Çil Anadolu High School, \\ Eskişehir, Turkey.
}

Received: November 15, 2018

Accepted: December 21, 2018

Online Published: February 26, 2019

doi:10.5539/ies.v12n3p105

URL: https://doi.org/10.5539/ies.v12n3p105

\begin{abstract}
The aim of this study is to determine the characteristics of the referees who have an important place in the football world where great developments are experienced day by day.

Football has grown incredibly and globalized in recent years. Many sports clubs and leagues constitute a large sector that extends far beyond the national community to international audiences. This global growth has enabled the expansion of financial resources, especially in the professional market sector. This development of football and clubs also affected the referee process. Now audiences, athletes and club managers expect the referees to show management that they are making less mistakes, making the right decisions, being fair, and preventing sports injuries from occurring. The referees are persons who are assigned to competitions by national and international federations that have the authority to administer the competition on the basis of rules. In many parts of the world, fans, athletes, coaches are often complaints about the judges' prejudice against the teams and their inadequacies. Referee decisions are very important in terms of a team winning the championship, falling league and competing in Europe. It is increasing day by day to criticize the judges 'behavior and decisions in the competition, especially since the clubs' ever-growing incomes and sales of TV broadcast rights are expressed in millions of dollars. In particular, the monitoring of the game field with many cameras and evolving video technology is closely examining the actions of the referees and the players in the closest distance and the number of repetitions too intensely. Referee also is an athlete. Hakem has to be nearest to the game, run as well as the players, have the mind open, and have to make the correct definition.

The aim of this study is to explain the mental suitcase of the referees, which is a new definition in the referee literature and which includes the mental processes of the referees before, during, and after the competition.
\end{abstract}

Keywords: sports, football, referee, mental characteristics, mental suitcase

\section{Introduction}

Football: The sport that all professional footballers, technical men, and even club managers earn serious money. The referees in the football are almost the most criticized and have the least share of the billions of dollars in turnover.

A fine line which separating success from failure has in sports. Often success or failure depends on decisions made by players and referees. For clubs and players, the economic consequences of success or failure may be great. Referees who are football authorities are under intense pressure from all sides to make their decisions as fair, consistent and correct as possible (Dawson, Dobson, Goddard, \& Wilson, 2007).

According to the Rules of the Football Game FIFA 2018/2019: Rule 3: The game is played between two teams, each consisting of a maximum of eleven (11) players, one of which is the goalkeeper (The International Football Association Board 2018/2019, p. 47). Rule 5.1: Each match is controlled by a referee who has full authority to enforce the Laws of the Game in connection with the match. Rule 5.2: Decisions will be made to the best of the referee's ability according to the Laws of the Game and the 'spirit of the game' and will be based on the opinion of the referee who has the discretion to take appropriate action within the framework of the Laws of the Game (The International Football Association Board 2018/2019, p. 63). 
For this reason, in a soccer game, the referees were given the opportunity to check the players for different violations and the game rules and the different violations during the whole game (Carmona \& Ortega, 2016).

One of the elements of football is the referees. The main thing is that the two teams compete and do sports. Audiences and media follow teams and actors. The referees are the person who makes the competition compliant with the rules and completes without dispute. The referee is very important, but the referee is not the main element of football, it is the auxiliary element. Many times we encountered the question "How was the referee?" The answers are usually "good, mediocre and bad". But when we do that we often consider different criteria. For example, while the decisions made for some are adequate, some are based on physical and mental status, others are based on behavior. There can be many details about the definition of "Good Referee". Especially in Europe, two basic features that determine the career of the jury are emphasized. These;

- Physical Fitness

- Mental Fitness

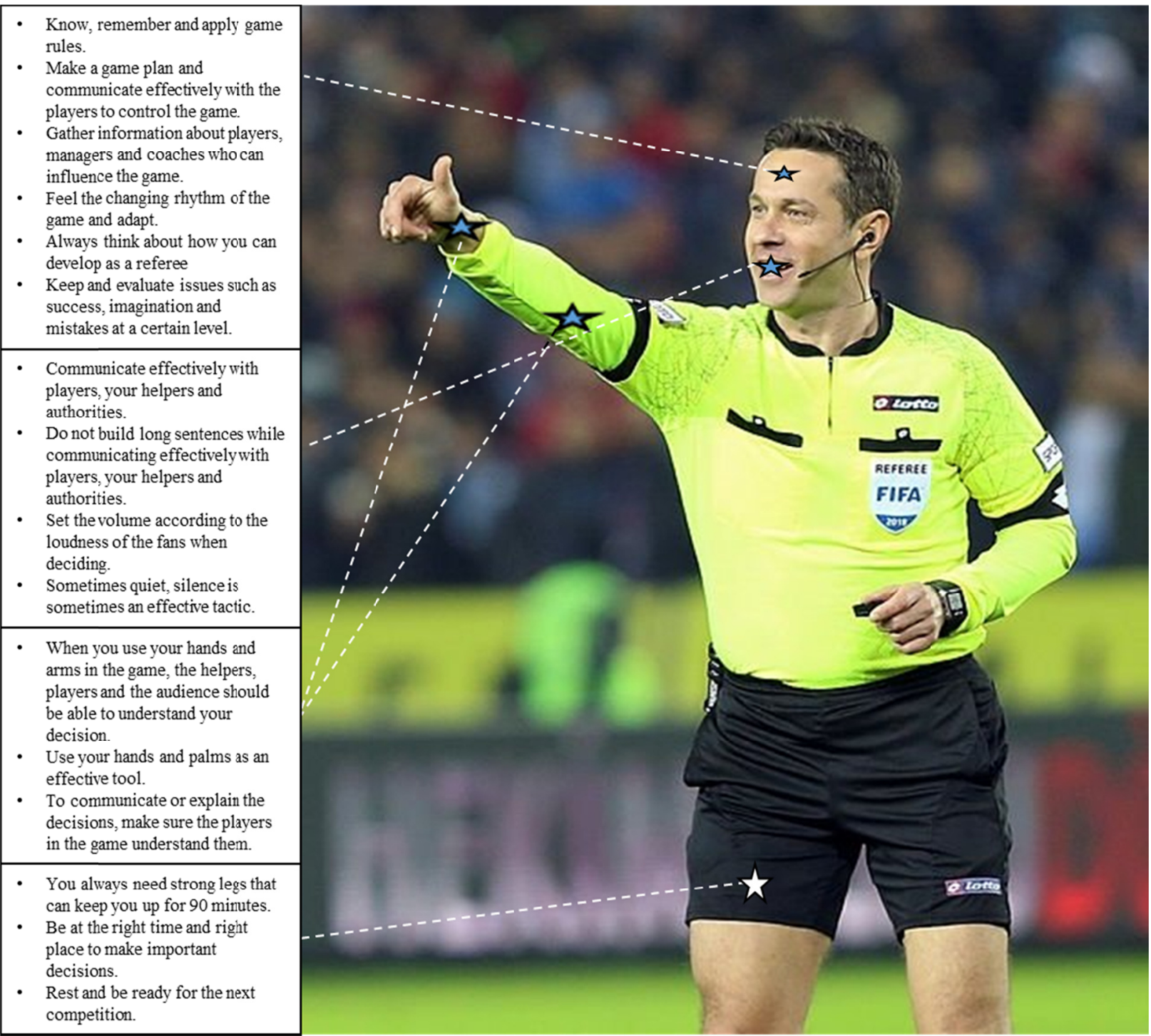

Figure 1a. Body parts and characteristics of modern referee (Meeson, 2014, p. 6.) 


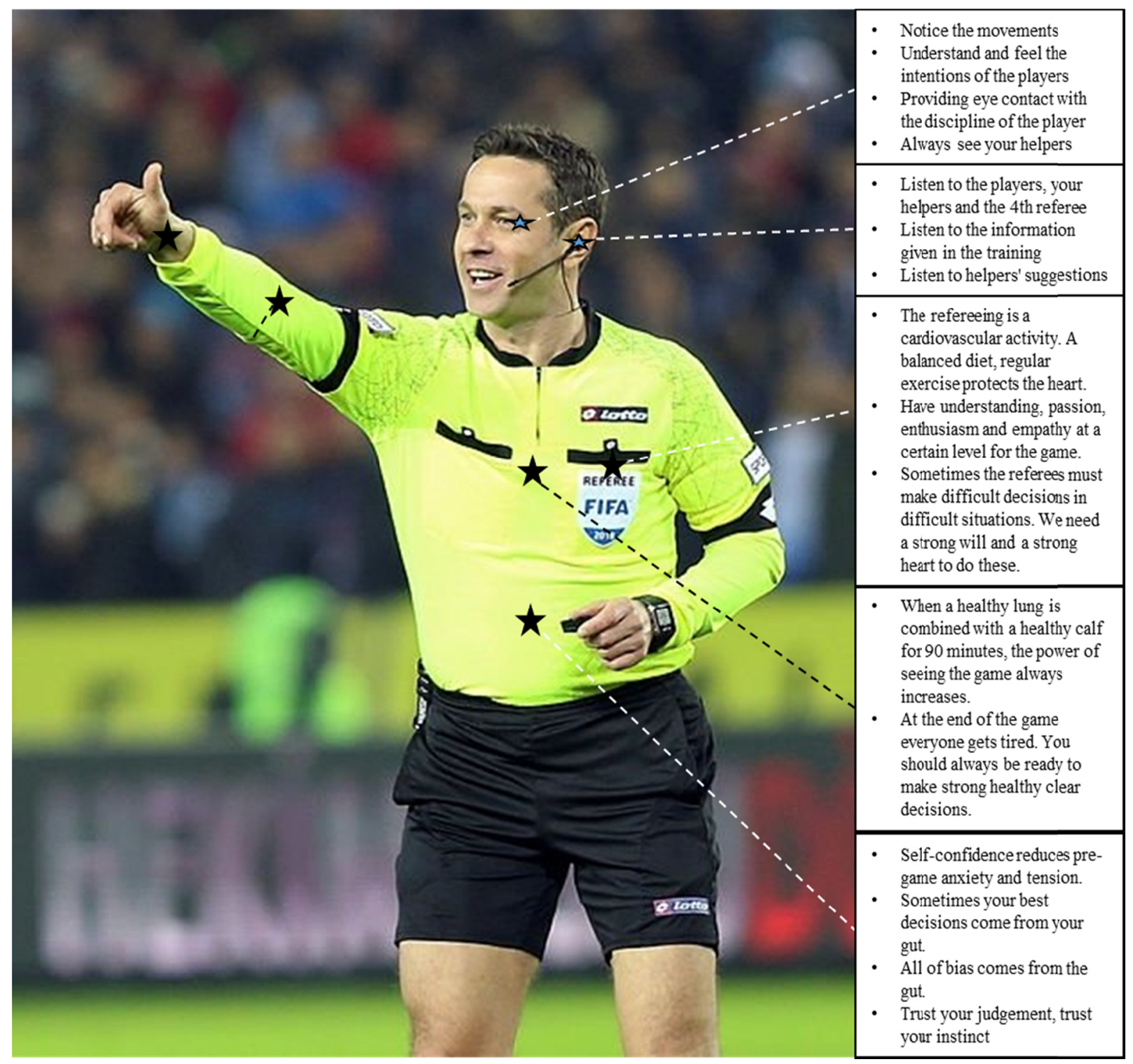

Figure 1b. Body parts and characteristics of modern referee (Meeson, 2014, p. 7)

Nowadays, modern referees must have a strong and athletic structure (with proper physical characteristics), as well as mental skills at various levels to make the right decisions. For example, the penalty area is a critical area for the referee to decide. Because ultimately the decision can be a penalty. It's an important decision in the penalty cast. Such a decision requires the closeness to the game (being in the right place to see the position) namely physical competence, courage and the right decision (mental processes). For this reason, the following basic factors should be considered in judging the court within the game (Taylor, Moss, \& Gae, 2014);

- How was the position of the judge before and during the position? Viewing angle appropriate?

- How was the initial reaction (position confirmation) at play?

- Were there preventative strategies to be proactive?

- Which support (team work) is waiting for your helpers? (If available)

- What action was not taken? (If available)

- What disciplinary penalty do you give? (If available)

- How do you start the game again?

- What kind of learning can you provide after the game? 
There is always a standard among the referee as the rule information. Almost every referee in the same category knows about the same rules. But what is important is the interpretation of these rules. It is necessary to interpret the movements and positions during the match appropriately. This is only a feature that the referees will win both physically and mentally before the competition. One of the most important factors for a good referee is the referee's personality. One of the most used words in the referee seminars organized by UEFA since 1973 is the 'personality'.

Personality; is the whole of the features that distinguish the individual from others, brought from birth and subsequently exhibited consistently. Personality includes the continuing aspects of the individual's mental, emotional, social, and physical characteristics (Özdemir, Özdemir, Kadak, \& Nasıroğlu, 2012). Human development is a complex process consisting of various basic dimensions such as physical, mental, social and moral development and there is a mutual relationship between each dimension. While some aspects of development are influenced by inheritance and some aspects are influenced by environment, many aspects are influenced by both (Çamlıbel, 2012).

Four distinctive features that exist in the personality core are (Baltaş, 2004):

- Consistency and honesty

- Decision and stability

- Proficiency

- To have a vision

When the above-mentioned definition of personality and the distinctive features of the personality core are examined, it is seen that each property overlaps with the characteristics that must be found in modern referees. As is known, UEFA Seminars are high-level referee seminars. And here we focus on the application, not the teaching of rules. Decisions given on competitions without pressure on the referee are usually closer to the standard. However, in the event that the spectator's, media's, player's, manager's and coach's pressure are concentrated on the referee in the matches, the award of standard decisions is proportional to the referee's personality. The referees who have the personality to resist the oppression are the modern referees who can continue standard management. For this reason, the modern referee must have his own two suitcases in every competition. The first one is the suitcase in which the refereeing materials are located. The second is the "mental suitcase" in which the referee carries personal qualities that are unique to itself and includes antidotes and mental tools that can be used at any time according to situational factors.

This suitcase can sometimes be very cluttered. So it's a suitcase we do not organize. You may also have a standard suitcase. There may be standards in this suitcase. Someone told you, but it is important that you organize and develop your suitcase according to your own methods. You need to open your suitcase and know what you want to use, and you should always be able to renew and prepare this case. This suitcase is about your mind map. So it is related to the situation before the match and the situations you will deal with during the match. When you realize that your Inner Motivation is falling down, remember that there are three antidotes to this situation in your suitcase, if you put it in it. These are; self-confidence-focus-redesign. The more you invest in your suitcase, the more success you will have. Strategies in the suitcase are always important. The antidote will be self confident in a competition where ninety thousand viewers are constantly shouting. A player can resist you verbally or in body language. The antidote to this is "emotional control". A player may foul in the penalty area. You need to give the right emotional response. For this reason, as an antidote in your suitcase, optimism-effective use of body language-authority (authority)-simplification of the claims and coolness must be found and eye contact with the player must be established. If these antidotes are not in your suitcase, it will always be difficult to fight pressure. In this suitcase (Terekli, 2009);

- Experience-Number of matches in the jury

- Strategies-Mental competence

- Anger-Point of view

- Anxiety-With calm

- Distress-interest, Focus and concentration

- Fear-Effective communication

- Use of planning incompleteness-Preliminary observations

- Eclipse-Behavior repertoire 
- $\quad$ Reacting to success and failure-Self awareness

What do you want from your match? First visualize it in your eyes. Match that moment and feel that moment with five emotions. Live in it. When you do this you will see missing antidotes in your suitcase and you will send your consciousness to this request. If you do not subconsciously ignore new positive things with your conscious mind, your subconscious will continue to carry on the modern life you know. Our unconscious is our coward. We are its master. Whatever we want, it makes it. In the first stage, we need to consciously place what we want to it. Thought happens in the mind, emotion becomes the body. It is a mood to transfer the new mind to the body. Do not forget! There is no failure, there are consequences. Look at the results. Edit the suitcase. Put a new action plan in your suitcase. And evaluate how you can use the information you get from these results. In the case of the above judgments, each referee must make preparations both before and during the season, both physically and mentally. This study does not focus on the physical characteristics that referees should have, but only on mental power.

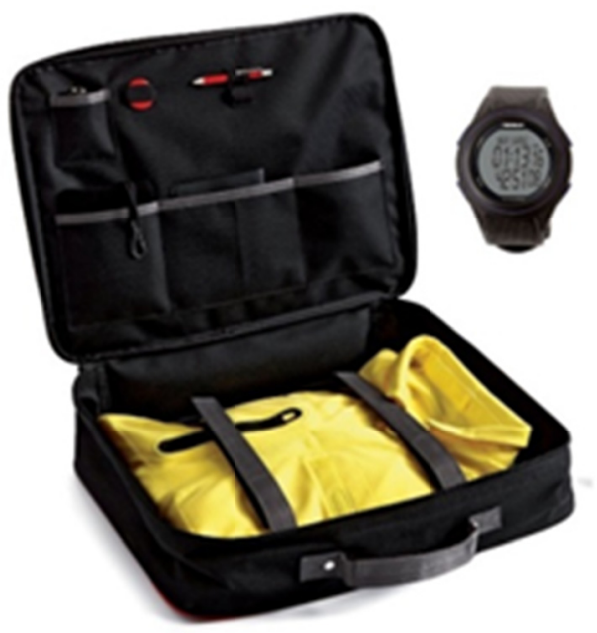

Figure 2. Referee material case

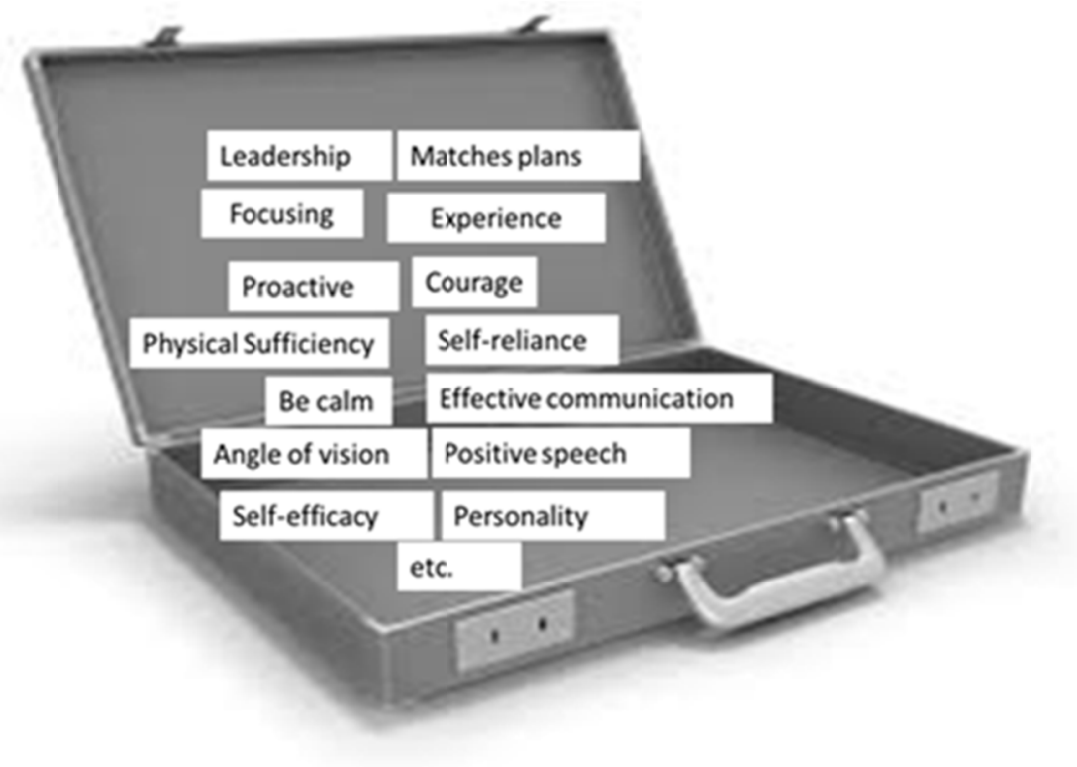

Figure 3. Mental suitcase (Terekli, 2009) 


\section{Mental Suitcase to Cope With Big Decision: Mental Power}

The main objective of the modern referee is to identify the strategies that will help to make the right decisions in the right way.

- Red cards (violent movements, serious foul play, spitting, using offensive language, insulting profanity, gestures and second warning)

- Penalty

- Critical offside decisions

- Controversial goals

- Holiday of the match

In the case of the above decisions, each referee must make preparations both before and during the season, both physically and mentally. The referees must always be in a position with no obstacles open in view of the game. A referee's quality depends on the viewing angle of the referee rather than proximity to the referee of the game. For this reason, the referee is considered to be a modern referee who is both good at sight and close to the game. Big decisions can be made at any time and anywhere in the game. For this reason, the referees must be physically proactive. From the beginning to the end of the match, he must make physical effort to make an ideal vision. The physical capacity of a court increases with mental fitness. They are under more pressure than ever to catch up with the game. A referee who is physically and mentally fit will be able to comfortably maintain a high-level match (Terekli, 2010).

The modern referee should reset the targets that were identified in the previous survey and set targets for the future. The referee must always be a model at every stage of life. The referee must have the ability to communicate well with people and always be comfortable when talking to a player or a club president. He must have a conversation with the football supporter. He must make every person valuable he speaks and should give a good impression of arbitration while sharing his views. Modern referee always has a professional approach. He is looking for personal performance and ways to improve his team's performance. On the day of the match, each member of the team must be assessed and made sure that each member has the best performance. Remember, the credibility of the team is stronger than the sum of the individual parts. In refereeing, role model behavior develops throughout the career of the referee. However, this model is definitely not underestimate. Because those who decide to rise in your career it is very important for this model. This is definitely not an ego. Because in the locker room is no place for any ego. Some referees may change with role model resulting from being a good referee. Maybe he can get obsessed with his own importance. You certainly do not let that happen. Always ask for honest, fair, learned, hardworking people around you (Terekli, 2013).

\subsection{Mental Power to Cope With Big Decisions}

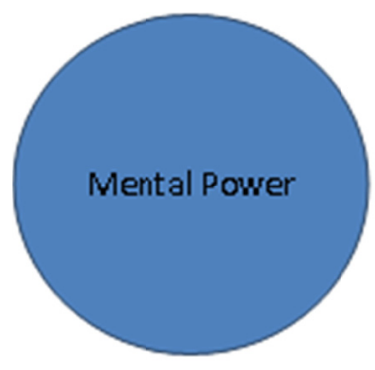

Emotion Control

Concentration

Courage

Reliability 


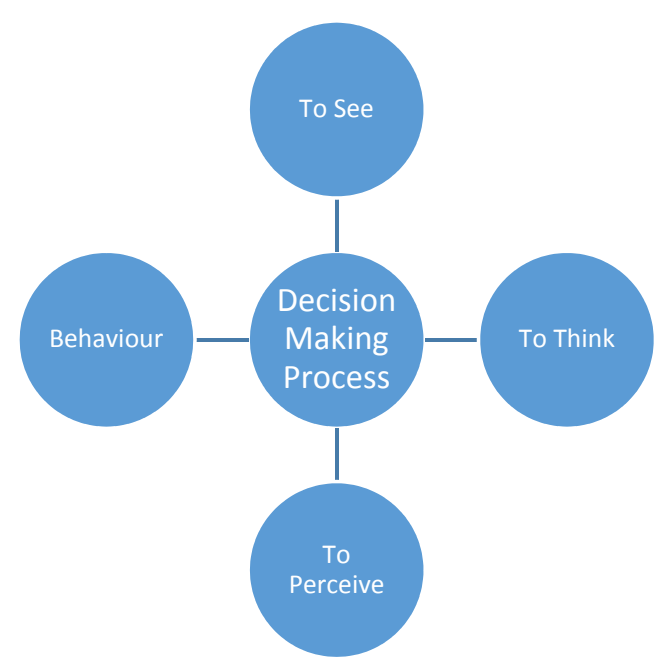

Figure 4. Mental power and decision making process (Fa Learning and the referees' association, 2014, p. 10)

Regardless of the level referees must have experience against players who object to decisions in various forms. This is a conflict. How will you avoid conflict? Who will play the role in such a situation? Now find the antidote to the cracker from your mental suitcase. The antidote that you can use in conflict is, of course, 'effective communication, calmness, proactive behavior and experience'. Under any circumstance, it is important to remember that we should not conceal any form of conflict. It can be handled in many ways. Sometimes a silent word is enough to silence the player. However, when a conflict action interrogates or weakens your authority, it must be handled in accordance with the rules of the game. Acting on the first opportunity is a vital proposition. It is important that you stay calm and professional when you think you are right. Don't forget! The referee can not expect an aggressive player to calm down. Your closeness to the game can be a vital tool in reducing the aggressive behavior as well as allowing the players to accept the decision made by the court. Remember, there are always such players. You have to be ready to move accordingly. In the first stage, clear and robust action is the key to sending a message to all actors and management that this kind of damaging action is unacceptable. First, find the person who creates the problem, and make an order according to the rules by looking in an objective perspective. Your application here will be two-way. The first is your observations and the other is the views of your team about the events that happen in your area or in the field you can not see. The development of this as a team depends on two compliance. These:

\section{- $\quad$ Task compliance}

\section{- Social compliance}

Here the referee and his team must use the task compliance throughout the competition. Social compliance using outside the game for enjoying the game, joking, etc. As long as the game continues, social adaptation must return to the task alignment. 


\subsection{Team Work in Modern Refereeing}

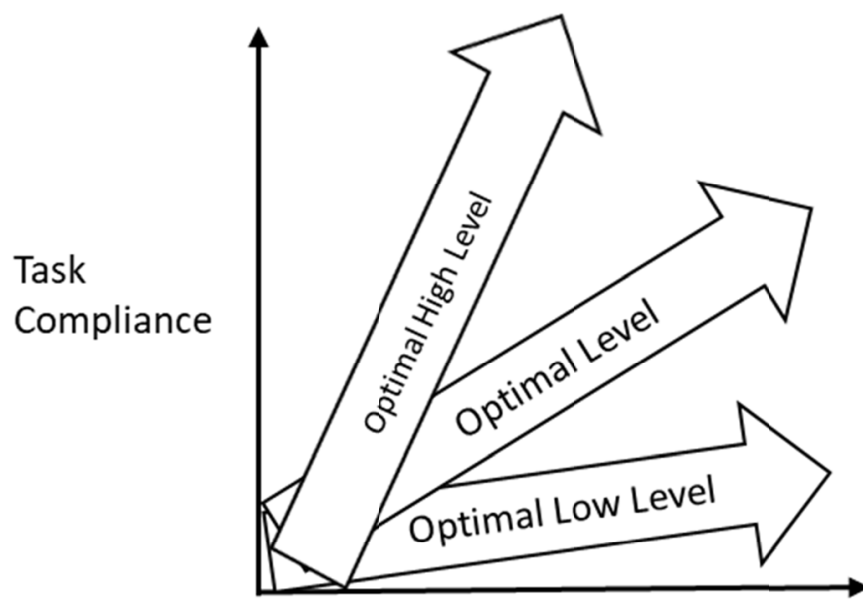

Social Compliance

Figure 5. Relationship between task compliance and social compliance (Terekli, 2013)

Task compliance is always very important for the referees. The referee and team performing task compliance perform optimally (higher level). Strategies that should be used to improve task compliance in modern refereeing are as follows:

- Regular team training (adds mental value)

- Transition from leadership to management (recognizing different situations in the game)

- Evaluation of expectations as a team (team compliance)

- Technical discussions (development of the learning process)

- Create an awareness of the team as part of the game preparation process (it is always helpful to identify the game strategy and be aware of it)

- Taking joint responsibility management (trust)

- Sharing is a communication culture (effective communication)

- Constructive criticism is very important. (error can always be)

- Establishing a spirit of healthy competition (task compliance)

- $\quad$ Long-term projects (continuity of the team)

\subsection{Mental Management}

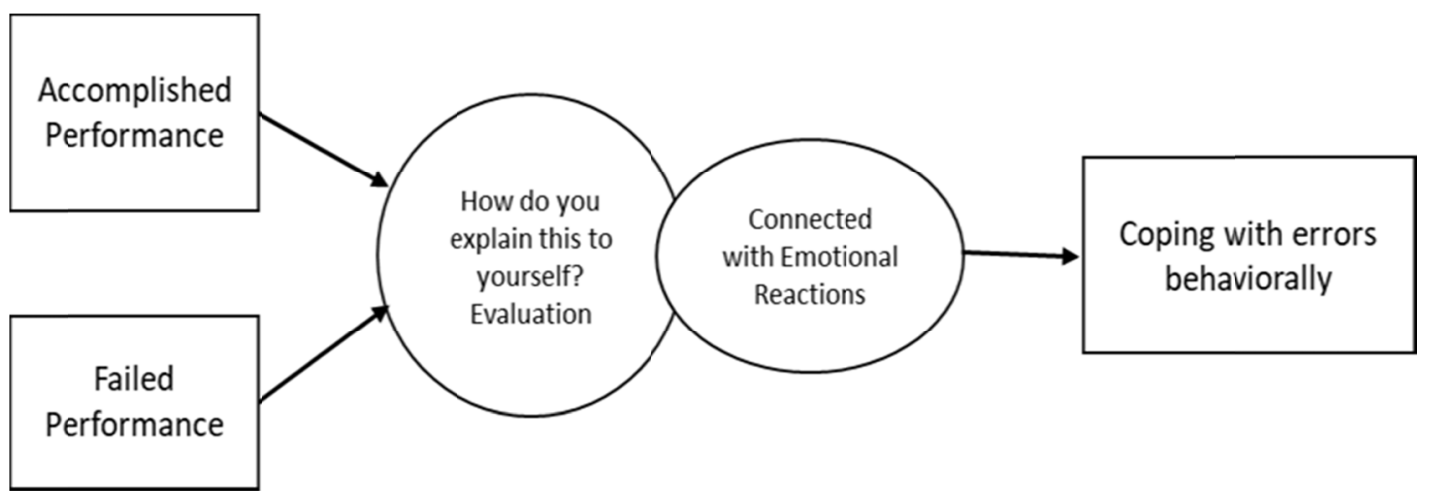

Figure 6. Mental management process (Terekli, 2009) 
Accomplished performance: to make good decisions, to make the right decisions, to manage a good match, to be assigned to a good match

Failed performance: Bad match, wrong decision.

The modern referee should consider the following criteria when applying mental management:

- Evaluate your decisions according to your personal criteria (Was I successful/Was I unsuccessful?).

- Integrate the observations of the observer and the mentor into these decisions.

- Balancing players and fans within the gaming atmosphere (Was I successful/Was I unsuccessful?).

- It is very difficult to deal with the media. Do not get serious about what the media says before the match and do not follow the media. After the match, trust your own self-analysis to keep up with the media.

- Try to find the answer to the question "What caused this mistake?" When evaluating a position in the competition.

- Check your internal resources (talent-skill) for successes. Internal causes will give you more right decisions.

- Maximize your personal responsibilities (Physical and mental power)

- Do not crime external factors (luck, spectators, etc.).

- Pre-match joy can reduce self-confidence. Do not use too much. Live in a more private environment. Shame and sadness can reduce confidence.

- Punishment makes other mistakes susceptible.

- Disillusion and guilt can trigger feelings of compensation.

- Do not stay connected to a fault. Go back, analyze, use stress and emotional techniques.

- Analyze the error, focus on the next situation.

- Focus on balanced game preparation. Look at critical situations, be realistic, create positive reactions.

- Open your mental power bag as a team and learn something as a team.

Trust is only a beginning for a good referee. The greatest need is; the ability to make the right decisions, communicate them effectively, and have the courage to make big and tough decisions when necessary. That is to protect the standards and the image of the game. Honesty, integrity, professionalism, self-evaluation, courage, determination must always be in your mental referee bag. Success can never be guaranteed. Always organize your mental suitcase for excellent performance. Even the best referee can not be perfect. You never have a magical ability. If it were, it would be very easy to believe that you were a modern referee. Work faithfully and do not hesitate to make sacrifices to realize your dreams. Check your mental suitcase for those who mind do the best that you can, and your ability to control. Always show a calm and confident environment. To succeed in the grand stage, trust your ability. This should never become arrogance. Be aware of this. If arrogance happens, your mind becomes confused and worries rise. We do not need to say, we do not need such a violent action (Terekli, 2011; Terekli, 2013).

No matter how well you work, your decision may not always be right. Here you have to work harder to get rid of this situation. What did you learn from the mistake you made? There is a way to return to your mental suitcase from this mistake. Find it and apply it. These studies will take you to the biggest stadiums and the most important matches in the world. Upper league referees in the football should be role models for the lower league referees. What are the features of a good role model? What do you need to stop and work on?

\subsection{Is There a Focus on Your Mental Suitcase?}

If there isn't focusing in your mental suitcase, then there is a problem with applying your modern referee. It is accepted that every good referee has the ability to maintain its focus throughout the game.

What is the focusing and how is it developed? How is it related to concentration? Now let's try to answer these questions. Focusing and concentration are different concepts. Players and spectators are just a few of the factors that cause distraction in you. Check your ballot in the game, hold it firmly in the game, ignore distractions and block it. Focus on what you want, not what you want to focus on. It is always useful to focus on success rather than success. There is always an aim to advance your game plan, your goals, your dreams and your desires. See what you focus on. While imagining that you are creating a focused and motivated image in your brain, take advantage of the ability to distinguish between reality and fantasy. Close your eyes for a moment and think that you are the referee in the best case, recreate the picture, sounds and feelings. Think about driving a car for the first time. This 
can be daunting for you. But when you focus on the important direction, you are consistently more competent in every field. You can develop a clear focus and concentration to strengthen your skills and understand each feature of the car. Finally you are equipped with the ability to drive the car at the right speed and safely. We always focus on something during refereeing but you need to focus on what's right. Think of two players running the same ball in the game. What will you focus on? Your concentration should always be the body shape of two athletes fighting for the ball. Now let's give a sample application to focus on (Blanchard, 2014):

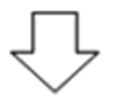

\section{DEVELOP CLEAR TARGETS}

These goals should be related to your referee performance. For example; I must be closer to the game. This is a performance target. It is a technical objective that can improve your decisions. So if you are working on your physical performance level (if you have the ability to sprint closer to the game) then you have every chance of achieving this goal.

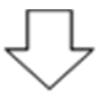

\section{APPLICATION IS ALWAYS FAVORABL}

David Beckham has consistently made free-throwing work with clearly defined targets about where the ball should go. Watch your decisions over and over again and work them. How far you are away from the game, see if you see what position the angle of view. What is your first act? Separate this process for manageable parts and repeat them.

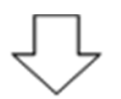

\section{MENTAL EDUCATION}

Using simple tasks will help increase your focus and concentration. Close your eyes and focus on your breath, move your chest while breathing. List each of your breathes, see what you have in mind or how many you can count before your attention breaks. If this number is ten or more then you are doing well. Do this twice a day and set a goal to increase the number. Your mental suitcase is very important for improving your referee performance. Open it, see what's missing, and try to be organized.

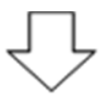

\section{FOCUS THE GAME}

Focus on the decision of ten referees using the above application. Exercise the above breathing, and when you breathe, make sure you pass one of the referee's decisions. Take a breath, for example, a corner kick and breathe out. Take a breathe-give the free kick and breathe out. Take a breathe-give the offside and breathe out. Take a breathe-give the penalty kick and breathe out. Take a breathe - make no foul decisions and breathe out. These studies allow you to focus on your core tasks by staying relaxed while making decisions that are important to you. In that case, the most important mental skill techniques that must be used by the referees (Slack, 2014):

- Goal setting

- Relaxation exercise

- Mental image

- Visualization

- Positive speech

- $\quad$ Focus and refocus

- Effective communication

- Anxiety management strategies

\section{Conclusion}

In the modern refereeing process, you should properly prepare the "mental suitcase" so that you can take part in the 
biggest stadiums and biggest matches, and have a good career, and try to carry along with you during your referee life. How would you think if you did not have your bag carrying the referee's goods, you would get out of the match? Or you opened your bag and realized that you did not have yellow and red cards. Your assistant referee did not bring his flag. What do you think about that? Here is the mental suitcase that you should always be with your bag and constantly renew. Get used to life with this bag. Because there are all the antidotes in it that will help you in the most important part of the game. Open your mental suitcase, find your antidote and use it. It's all that easy.

\section{References}

Baltaş, A. (2004). Leadership personality. Source Journal, 17, 1. Retrieved from http://www.kaynakdergisi.net/ makaleler.asp? sayi $=17 \&$ sira $=389$

Blanchard, I. (2014). Focus and concentration in refereeing. Refereeing, 22, 10. Retrieved from https://www.the-ra.org/assets/Referee\%20Magazine\%20Volume\%2022\%20single.pdf

Carmona, C. G., Ortega, J. P. (2016). Kinematic and physiological analysis of the performance of the referee football and its relationship with decision making. Journal of Human Sport \& Exercise, 4(11), 397-414. https://doi.org/10.14198/jhse.2016.114.01

Çamlıbel, İ. A. (2012). Children's development process and the effects of television (Master thesis, Ankara, Radio and Television Supreme Council).

Dawson, P., Dobson, S., Goddard, J., \& Wilson, J. (2007). Are Football Referees Really Biased and Inconsistent? Evidence on the Incidence of Disciplinary Sanction in the English Premier League. Journal of the Royal Statistical Society: Series A-Statistics in Society, 170(1), 231-250. https://doi.org/10.1111/j.1467-985x.2006.00451.x

Fa Learning and the referees' association. (2014). Mental strength to cope with big decisions. Refereeing, 23, 10. Retrieved from https://www.the-ra.org/assets/Referee\%20Magazine\%20Volume\%2023\%20single.pdf

Meeson, D. (2014). Physical attributes of a modern day referee. Refereeing, 23, 6-7. Retrieved from https://www.the-ra.org/assets/Referee\%20Magazine\%20Volume\%2023\%20single.pdf

Özdemir, O., Özdemir, P. G., Kadak, M. T., \& Nasiroğlu, S. (2012). Personality Development. Current Approaches in Psychiatry, 4(4), 566-589. https://doi.org/10.5455/cap.20120433

Slack, L. (2014). Controlling the controllables: Coping with refereeing pressures. Refereeing, 22, 14. Retrieved from https://www.the-ra.org/assets/Referee\%20Magazine\%20Volume\%2022\%20single.pdf

Taylor, A., Moss, J., \& Gae, G. (2014). Controlling the penalty area. Refereeing, 23, 8. Retrieved from https://www.the-ra.org/assets/Referee\%20Magazine\%20Volume\%2023\%20single.pdf

Terekli, M. S. (2009). Turkish Football Federation, Central Referee Board. International Referee Seminar Notes. Silivri, İstanbul. 30/07-01/08.

Terekli, M. S. (2010). Turkish Football Federation, Central Referee Board. International Referee Seminar Notes. Silivri, İstanbul. 28/07-01/08.

Terekli, M. S. (2011). Turkish Football Federation, Central Referee Board. International Referee Seminar Notes. Silivri, İstanbul. 24/07-27/07.

Terekli, M. S. (2013). Turkish Football Federation, Central Referee Board. International Referee Seminar Notes. Antalya. 08-11/01.

The International Football Association Board. (2018/2019). Retrieved from http://static-3eb8.kxcdn.com/ documents/662/065106_170818_LotG_18_19_EN_SinglePage_150dpi_Korr.pdf

\section{Copyrights}

Copyright for this article is retained by the author(s), with first publication rights granted to the journal.

This is an open-access article distributed under the terms and conditions of the Creative Commons Attribution license (http://creativecommons.org/licenses/by/4.0/). 